\title{
Ceruloplasmin Protects Against Rotenone-Induced Oxidative Stress and Neurotoxicity
}

\author{
Akiyo Hineno • Kazuma Kaneko • Kunihiro Yoshida • \\ Shu-ichi Ikeda
}

Accepted: 18 June 2011/Published online: 26 June 2011

(C) The Author(s) 2011. This article is published with open access at Springerlink.com

\begin{abstract}
To clarify the neuroprotective property of ceruloplasmin and the pathogenesis of aceruloplasminemia, we generated ceruloplasmin-deficient $\left(\mathrm{CP}^{-/-}\right)$mice on the C57BL/10 genetic background and further treated them with a mitochondrial complex I inhibitor, rotenone. There was no iron accumulation in the brains of $C P^{-/-}$ mice at least up to 60 weeks of age. Without rotenone treatment, $C P^{-I-}$ mice showed slight motor dysfunction compared with $C P^{+/+}$mice, but there were no detectable differences in the levels of oxidative stress markers between these two groups. A low dose of rotenone did not affect the mitochondrial complex I activity in our mice, however, it caused a significant change in motor behavior, neuropathology, or the levels of oxidative stress markers in $\mathrm{CP}^{-/-}$mice, but not in $\mathrm{CP}^{+/+}$mice. Our data support that ceruloplasmin protects against rotenone-induced oxidative stress and neurotoxicity, probably through its antioxidant properties independently of its function of iron metabolism.
\end{abstract}

Keywords Ceruloplasmin · Iron · Rotenone · Oxidative stress $\cdot$ Antioxidant

A. Hineno $\cdot$ K. Kaneko $\cdot$ K. Yoshida $(\bowtie) \cdot$ S. Ikeda Department of Medicine (Neurology and Rheumatology), Shinshu University School of Medicine, Matsumoto 390-8621, Japan

e-mail: kyoshida@shinshu-u.ac.jp

K. Yoshida

Division of Neurogenetics, Department of Brain Disease Research, Shinshu University School of Medicine, Matsumoto 390-8621, Japan

\section{Introduction}

Ceruloplasmin $(\mathrm{Cp})$ is proposed to have multiple biological functions, including oxidation of ferrous iron $\left(\mathrm{Fe}^{2+}\right)$ and oraganic amines, copper transport, radical scavenging, and prooxidant activities [1-3]. In particular, the significance of $\mathrm{Cp}$ in iron transport through its ferroxidase activity has been well established, In the brain, Cp is mainly produced by astrocytes, especially perivascular astrocytes, and is localized on the membrane of astrocytes as a GPI-anchored form [4]. GPI-anchored $\mathrm{Cp}$ oxidizes $\mathrm{Fe}^{2+}$ released from perivascular astrocytes into ferric iron $\left(\mathrm{Fe}^{3+}\right)$, and allows it to bind to transferrin [5-7]. Transferrin-bound iron is the main source of iron for neurons, thus, $\mathrm{Cp}$ facilitates iron uptake of neurons by its ferroxidase activity.

In the $\mathrm{Cp}$-deficient state (aceruloplasminemia), $\mathrm{Fe}^{2+}$ in the interstitial space cannot be oxidized for uptake by transferrin. This might result in an increase of non-transferrin-bound iron (NTBI), and excessive NTBI then enters in astrocytes or other brain cells [5]. Finally, excessive cytosolic $\mathrm{Fe}^{2+}$ promotes the generation of cytotoxic hydroxyl radicals $\left(\mathrm{OH}^{*}\right)$, leading to the oxidative damage to neuronal cells. Indeed, a huge amount of iron accumulation is observed in various brain regions of aceruloplasminemia patients [8-10]. There are several lines of evidence supporting that increased oxidative stress is closely associated with neuronal cell death in this disease [913]. Therefore, aceruloplasminemia is a good model disease to investigate the pathogenetic link between iron accumulation and neurodegeneration. To assess this issue, we generated $\mathrm{Cp}$-deficient $\left(\mathrm{CP}^{-/-}\right)$mice by a targeted disruption of the ceruloplasmin gene $(C P)$ on the BALB/c genetic background [14]. Contrary to our expectation, however, our $C P^{-1-}$ mice showed no iron accumulation in the brain or apparent neurological dysfunction, whereas 
they developed a large amount of iron accumulation in the liver [14]. The conversion of genetic background of $C P^{-1-}$ mice from $\mathrm{BALB} / \mathrm{c}$ to $\mathrm{C} 57 \mathrm{BL} / 10$ also failed to develop iron accumulation (unpublished data).

It is widely believed that iron accumulation is involved in the pathogenesis of several neurodegenerative diseases such as Parkinson's disease and Alzheimer's disease [7, 15-17]. In Parkinson's disease, iron accumulation promotes $\alpha$-synuclein aggregation in the dopaminergic neurons of the substantia nigra [15-17]. Furthermore, excessive iron reduces the mitochondrial complex I activity in dopaminergic neurons [18]. Therefore, rotenone, a selective mitochondrial complex I inhibitor, has been used to reproduce the neuropathological findings of Parkinson's disease [19-26]. The neurotoxic properties of rotenone are mediated via $\mathrm{OH}^{\bullet}$ generation following the inhibition of complex I activity in the substantia nigra [20]. To date, many researchers have attempted to attenuate the neurotoxic effects of rotenone using various therapeutic agents in in vitro and in vivo models [27-29]. On the other hand, there are several clinical observations suggesting that a decreased oxidative activity of $\mathrm{Cp}$ is closely involved in the pathogenesis of Parkinson's disease [30, 31].

Our $\mathrm{CP}^{-1-}$ mice with both $\mathrm{BALB} / \mathrm{c}$ and $\mathrm{C} 57 \mathrm{BL} / 10$ genetic background showed no detectable iron accumulation. Therefore, this study aimed to investigate the neuroprotective properties of $\mathrm{Cp}$ independently of iron metabolism. For this aim, we treated the mice with rotenone to enhance oxidative stress and neurotoxicity.

\section{Experimental Procedure}

\section{Experimental Animals}

The derivation of the $C P^{-1-}$ mice with the C57BL/10 genetic background used in this study has been already described [14, 32]. All animals were housed in a controlled-temperature environment maintained under a $12 \mathrm{~h} /$ $12 \mathrm{~h} \mathrm{light/dark}$ cycle and provided with free access to food and water. All animal procedures were in accordance with the National Institutes of Health Guide for the Care and Use of Laboratory Animals and they were approved by the Institutional Animal Care and Use Committee of Shinshu University.

\section{Genotyping}

Tail tips were placed in a cell lysis solution (QIAGEN) supplemented with proteinase $\mathrm{K}(20 \mathrm{mg} / \mathrm{ml})$, shaken overnight at $55^{\circ} \mathrm{C}$, and then centrifuged for $5 \mathrm{~min}$ at $15,000 \times g$ at $4^{\circ} \mathrm{C}$ to remove insoluble material. The supernatant was directly subjected to PCR amplification with the Ampdirect Plus Kit (Shimadzu, Japan) for genotyping. The PCR conditions and primer sequences were described previously [14]. The genotype of the mice was reconfirmed by immunoblotting for serum $\mathrm{Cp}$ [14].

\section{Rotenone Treatment}

We used 13-week-old $C P^{+/+}$and $C P^{-/-}$mice in this study. The mice were treated with $10 \mathrm{mg} / \mathrm{kg} / \mathrm{day}$ rotenone or vehicle for 28 days using an osmotic pump (Alzet; DURECT Corporation, USA) subcutaneously, as previously described [32]. To see the effects of $\mathrm{Cp}$ under rotenoneinduced neurotoxic conditions, we established the following four types of mice: (1) rotenone-untreated, wild-type mice $\left(C P^{+/+} / \mathrm{R}-\right)$; (2) rotenone-untreated, Cp-deficient mice $\left(C P^{-1-} / \mathrm{R}-\right)$; (3) rotenone-treated, wild-type mice $\left(C P^{+/+} / \mathrm{R}+\right)$; and (4) rotenone-treated, $\mathrm{Cp}$-deficient mice $\left(C P^{-1-} / \mathrm{R}+\right)$.

\section{Behavioral Analysis}

In all animal groups, body weight and motor function were determined weekly during the period of treatment with rotenone or vehicle. Behavioral analysis was done by footprint assessment and accelerated rotarod test [33, 34].

Footprint assessment was performed to detect deficits in motor coordination and gait abnormalities. To obtain footprints, the hind- and forepaws of mice were coated with black and red nontoxic paint, respectively. The animals were then allowed to walk along a plastic-lined, $65 \mathrm{~cm}$ long and $4 \mathrm{~cm}$-wide walkway into an enclosed box with $12 \mathrm{~cm}$-high walls on either side. The footprint patterns were analyzed for stride length (the average distance of forward movement between each stride) and step alternation (the average distance from the left or right front footprint/hind footprint overlap) [33].

Motor coordination, balance, and learning were tested with an accelerating rotarod $(3.3 \mathrm{~cm}$ in diameter). The mice were allowed to run while the speed of the rotarod was gradually increased from 4 to $40 \mathrm{rpm}$. The mice were tested three times in each trial, and the mean latency to fall off the rotarod was recorded [34].

\section{Brain tissue Preparation}

After 4 weeks of treatment with rotenone or vehicle, all mice were deeply anesthetized with diethyl ether inhalation. The mice were euthanized and their whole brains were removed. One hemisphere of the removed brain was weighed and homogenized in a 10-fold volume of a high salt buffer (10 mM TrisHCl, pH 7.5, 0.5 M NaCl, $10 \%$ sucrose) supplemented with a cocktail of protease inhibitors (Complete Mini, Roche). The samples were 
centrifuged at $20,000 \times g$ for $20 \mathrm{~min}$, and the supernatants were stored at $-80^{\circ} \mathrm{C}$ until analysis. The other hemisphere of the brain was fixed overnight in $10 \%$ formalin for immunohistochemical analysis.

\section{Measurement of Mitochondrial Complex I Enzyme Activity}

We measured the mitochondrial complex I activities in brain and liver tissue homogenates using the Complex I Enzyme Activity Microplate Assay Kit (MitoSciences, USA). The samples recovered from whole tissue homogenates (protein concentration; $3.0 \mathrm{mg} / \mathrm{ml}$ for brain and $5.5 \mathrm{mg} / \mathrm{ml}$ for liver) were used for the assay according to the manufacturer's instructions. The activity was expressed as the change in absorbance at $450 \mathrm{~nm}$ per minute (mOD/ $\min )$.

\section{Assessment of Oxidative Stress Markers}

\section{Western Blotting}

Brain tissues were homogenized and boiled for $5 \mathrm{~min}$ in a buffer containing 10\% SDS, $70 \mathrm{mM}$ Tris- $\mathrm{HCl}(\mathrm{pH} 6.7)$, $10 \mathrm{mM}$ EDTA, and 5\% $\beta$-mercaptoethanol. Equal amounts of brain proteins were then separated on a graduated $12 \%$ SDS-polyacrylamide gel and electrotransferred onto a polyvinylidene difluoride membrane. The blot was incubated at $4^{\circ} \mathrm{C}$ overnight with the following primary antibodies: anti-Cp polyclonal antibody (Cp, 1:500, DAKO), anti-4-hydroxynonenal monoclonal antibody (HNE, 1:500, JaICA, Japan), and anti-Hexanoyl-Lysadduct monoclonal antibody (HEL, 1:500, JaICA, Japan).

After three washes, the membrane was incubated with secondary antibody (horseradish peroxidase-conjugated anti-mouse or rabbit IgG, 1:5,000, BioRad) and developed using ECL Western blotting detection reagents (Thermo, USA). To ensure that equal amounts of proteins were loaded, the same membranes were reprobed with antiglyceraldehyde 3-phosphate dehydrogenase monoclonal antibody (GAPDH, 1:5,000, Millipore).

\section{Immuno-Assay}

To measure the levels of the lipid peroxidation product 4-hydroxynonenal (HNE) in brain tissue, we used the 4-HNE-histidine ELISA Kit (OxiSelect HNE-His Adduct ELISA Kit, Cell Biolabs, New Zealand) according to the manufacturer's instructions. As the anti-HNE-His antibody was a monoclonal mouse $\mathrm{IgG}$, we used magnetic beads linked to protein $G$ (Dynabeads Protein G, Invitrogen Dynal, USA) to remove endogenous IgG from brain tissues [35]. To capture the endogenous IgG with Dynabeads protein $\mathrm{G}$, the same amount $(5 \mu \mathrm{g})$ of brain proteins was added to $50 \mu \mathrm{l}$ of beads and incubated with rotation overnight. Then the tube was placed onto a magnet to separate the beads from solution, and the supernatant was used for analysis.

The carbonyl contents of brain tissues were assayed with the Protein Carbonyl Enzyme Immuno-assay Kit (Biocell PC Test, BioCell Crop, New Zealand) according to the manufacturer's instructions. Absorbance was measured at $450 \mathrm{~nm}$ and expressed as nmol carbonyl/mg protein.

\section{Immunohistochemistry}

The paraffin-embedded brain tissues were cut at $10 \mu \mathrm{m}$. The sections were deparaffinized and hydrated through graded alcohol. These sections were first microwaved in $0.1 \mathrm{M}$ sodium citrate, $\mathrm{pH}$ 6.5. They were then incubated in $3 \%$ aqueous hydrogen peroxide $\left(\mathrm{H}_{2} \mathrm{O}_{2}\right)$ to remove endogenous peroxidase activity, and in phosphate buffered saline containing $10 \%$ goat serum for $30 \mathrm{~min}$. Subsequently, the sections were incubated overnight at $4^{\circ} \mathrm{C}$ with primary antibodies: HNE (1:100) and HEL (1:50). The sections were then incubated with anti-mouse or rabbit IgG secondary antibody (1:300, DAKO), streptavidin-HRP conjugate $(1: 300$, GIBCO $\mathrm{BRL})$, and reacted with diaminobenzidine $(0.3 \mathrm{mg} / \mathrm{ml}$, SIGMA) in $50 \mathrm{mM}$ Tris buffer $(\mathrm{pH} 7.4)$ with $0.001 \% \mathrm{H}_{2} \mathrm{O}_{2}$. Finally, the sections were counterstained with hematoxylin.

\section{Statistical Analysis}

All values are presented as mean \pm standard error (SEM). Statistical analysis of data was performed using two-way analysis of variance (ANOVA) or repeated-measures ANOVA, followed by post hoc Student's $t$-test to determine the significance of differences between two groups. The analysis was performed using software Excel Toukei 2010 (Social Survey Research Information, Tokyo, Japan). Statistical significance was attributed as $P<0.05$.

\section{Results}

Effects of Rotenone Treatment on Motor Function

All mice completed the protocol without any troubles in general health. There were no significant differences in body weight between the four experimental groups (data not shown). By western blotting, rotenone treatment did not change the level of $\mathrm{Cp}$ expression in $\mathrm{CP}^{+/+}$mice (Fig. 1a). There were no significant differences in mitochondrial complex I enzyme activity of brain (Fig. 1b) and liver tissue homogenates (Fig. 1c) among the four experimental groups. 

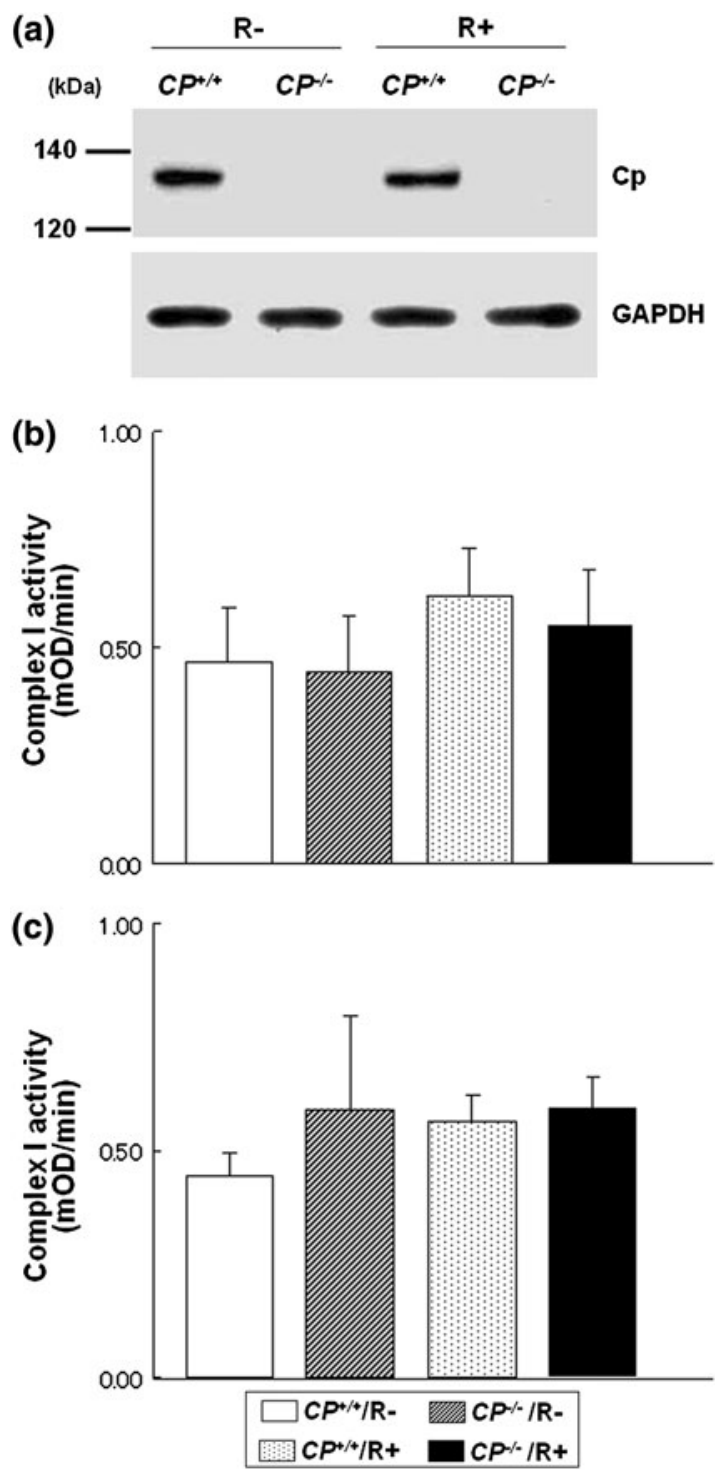

Fig. 1 Western blotting of brain homogenates using an anti-Cp antibody (a) and measurement of mitochondrial complex I activity in the brain (b) and liver (c). Cp expression was unchanged between $\mathrm{CP}^{+/+} / \mathrm{R}-$ and $C P^{+/+} / \mathrm{R}+$ mice (a). There was no significant difference in mitochondrial complex I enzyme activity of brain (b) and liver tissue homogenates (c) among the four experimental groups $(\mathrm{n}=5)$

In the footprint test, $C P^{-1-} / \mathrm{R}+$ mice tended to develop gait abnormalities, such as a shorter stride length and an irregular placement of the fore- and hind-limbs (Fig. 2a). Stride length significantly decreased in $C P^{-1-} / \mathrm{R}-$ mice $(0 \mathrm{w}: 64.0 \pm 4.0 \mathrm{~mm}$ vs. $4 \mathrm{w}: 54.4 \pm 3.3 \mathrm{~mm}, P<0.05$, $\mathrm{n}=8)$ and $C P^{-I-} / \mathrm{R}+$ mice $(0 \mathrm{w}: 63.5 \pm 1.3 \mathrm{~mm}$ vs. $4 \mathrm{w}$ : $53.6 \pm 2.3 \mathrm{~mm}, P<0.05, \mathrm{n}=6$ ) during the experiment, while there was no obvious change in $\mathrm{CP}^{+/+}$mice, even with rotenone treatment. There was no difference in stride length between $C P^{-1-} / \mathrm{R}-$ and $C P^{-/-} / \mathrm{R}+$ mice. Step alternation of $C P^{-/-}$mice appeared more irregular than in
$C P^{+/+}$mice before treatment, but this was not statistically significant. Step alteration gradually worsened with rotenone treatment in $\mathrm{CP}^{-/-}$mice. In $\mathrm{CP}^{+/+}$groups, step alteration tended to get worse with rotenone treatment, but the difference was not significant between $C P^{+/+} / \mathrm{R}-$ and $C P^{+/+} / \mathrm{R}+$ mice after 4 weeks. At the end of rotenone treatment, step alteration was more conspicuous in $\mathrm{CP}^{-/-}$/ $\mathrm{R}+$ mice than $C P^{+/+} / \mathrm{R}-$ or $C P^{+/+} / \mathrm{R}+$ mice (Fig. 2c). The time spent on the rotarod was not different before rotenone treatment between the four mouse groups, and increased over time in all groups. The fall latency of $\mathrm{CP}^{+\prime}$ ${ }^{+} / \mathrm{R}-$ mice drastically increased at 4 weeks $(0 \mathrm{w}$ : $10.8 \pm 2.7$ s vs. $4 \mathrm{w}: 41.2 \pm 4.0 \mathrm{~s}, P<0.05, \mathrm{n}=5$ ). However, after 4 weeks, $C P^{-1-} / \mathrm{R}-$ mice and $C P^{-/-} / \mathrm{R}+$ mice showed shorter fall latencies than $C P^{+/+} / \mathrm{R}-$ mice (Fig. 2d). There was no significant difference in the fall latency between the $C P^{-1-} / \mathrm{R}-$ and $C P^{-1-} / \mathrm{R}+$ mice.

\section{Detection of Oxidative Stress Markers}

Western blotting showed that the signals indicative of HNE and HEL were enhanced in the brains of $\mathrm{CP}^{-/-} / \mathrm{R}+$ mice compared with mice from the other three groups (Fig. 3a, b). Consistent with the western blotting data, ELISA analyses showed a significant increase in HNE and protein carbonyls in $C P^{-/-} / \mathrm{R}+$ mice (Fig. 3c, d). Rotenone treatment did not change the levels of HNE or carbonyl proteins in $C P^{+/+}$mice.

Neuropathological and Immunohistochemical Findings

Histopathological findings were grossly normal in the four experimental groups. Iron staining detected no iron accumulation in the brains of $C P^{-1-}$ mice before and after rotenone treatment (data not shown). The immunoreactivity for HNE and HEL in the cytoplasms of the striatal neurons was more conspicuous in $C P^{-1-} / \mathrm{R}+$ mice than $C P^{+/+} / \mathrm{R}-$ or $C P^{-/-} / \mathrm{R}-$ mice (Fig. 4). Even without rotenone treatment, the immunoreactivity was apparent in $C P^{-/-} / \mathrm{R}-$ mice, but not in $C P^{+/+} / \mathrm{R}-$ mice (Fig. 4).

\section{Discussion}

We have generated $C P^{-1-}$ mice in both the BALB/c and C57BL/10 genetic background to investigate the pathogenesis of aceruloplasminemia, but neither of the mice showed iron accumulation in the brain at least up to 40 or 60 weeks of age $[14,32]$. In this study, therefore, we used a selective mitochondrial complex I inhibitor, rotenone, to enhance oxidative stress and to see whether $\mathrm{Cp}$ has a protective effect against oxidative neuronal damage. Rotenone decreases the viability of TH-immunoreactive 
Fig. 2 Analysis of motor function. a Representative footprints after the 4-week administration of $10 \mathrm{mg} / \mathrm{kg}$ rotenone or vehicle. The forepaws and hindpaws were colored with red and black ink, respectively. The dotted lines indicate stride length. The irregular distance between the fore- and hindpaws in a $C P^{-/-}$, $\mathrm{R}+$ mouse is indicated by the bidirectional arrow. The quantification of the stride length (b) and step alternation (c) of footprint patterns in $C P^{+/}$ ${ }^{+} / \mathrm{R}-, C P^{-/-} / \mathrm{R}-, C P^{+/+} / \mathrm{R}+$, and $C P^{-1-} / \mathrm{R}+$ mice are shown $(\mathrm{n}=7-10)$. d Fall latency in the rotarod test (4-40 rpm) ( $\mathrm{n}=4-5) .{ }^{*} P<0.05$ in comparison with control $\left(\mathrm{CP}^{+/+} / \mathrm{R}-\right)$ (a)

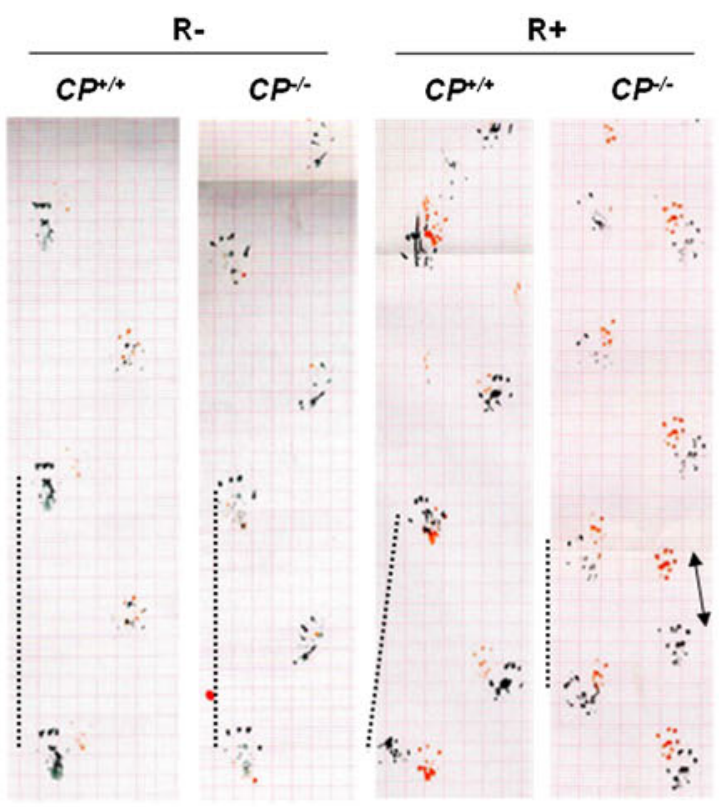

(b) $(\mathrm{cm})$

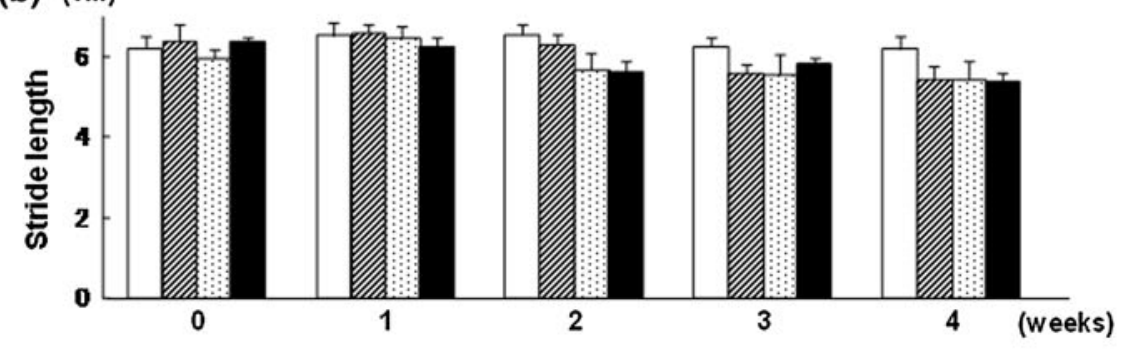

(c) $(\mathrm{mm})$
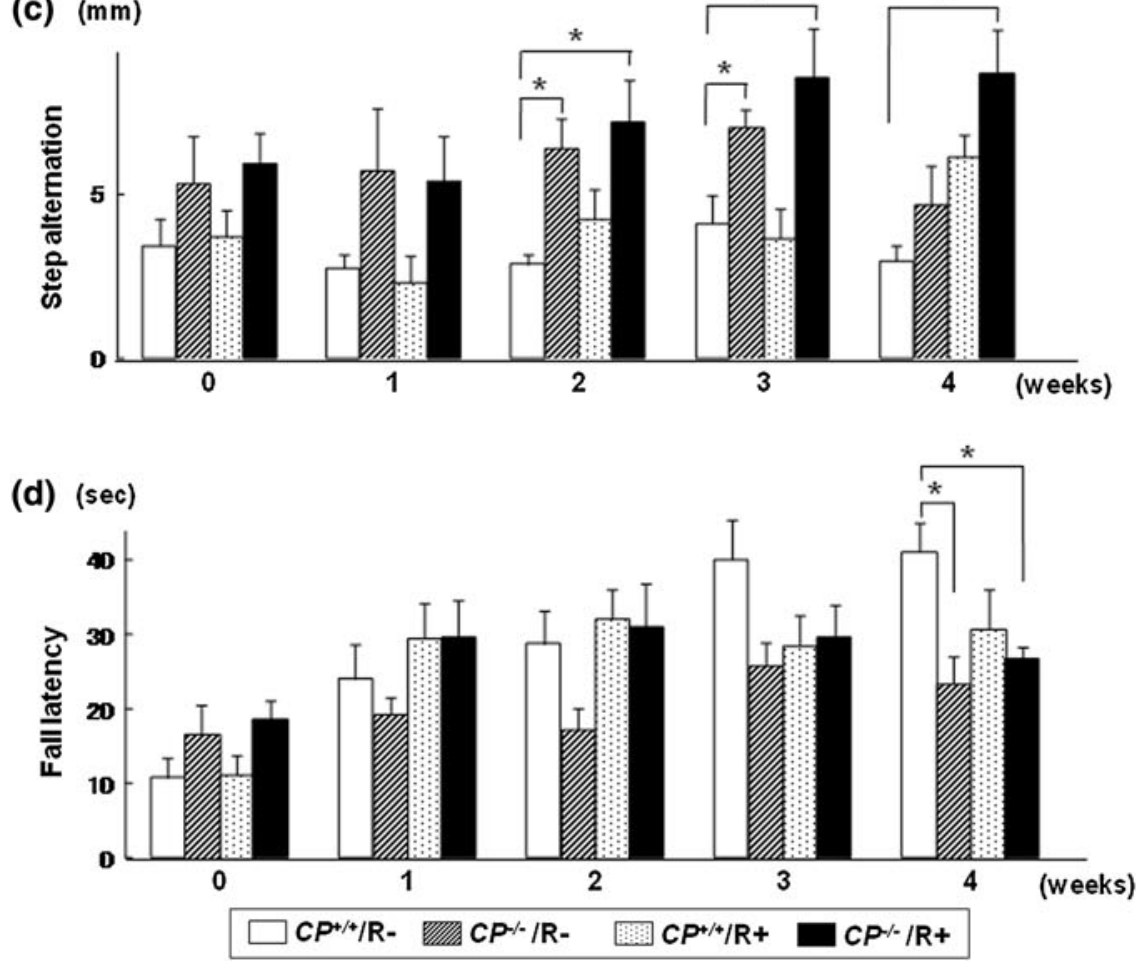
Fig. 3 Western blotting (a, b) and immune-assay $(\mathbf{c}, \mathbf{d})$ for oxidative stress markers. Western blotting for HNE (a), and HEL (b) is shown. The arrows indicate endogenous $\operatorname{IgG}(\mathbf{a}, \mathbf{b})$. Immuno-assay for HNE (c) and protein carbonyls (d) is shown
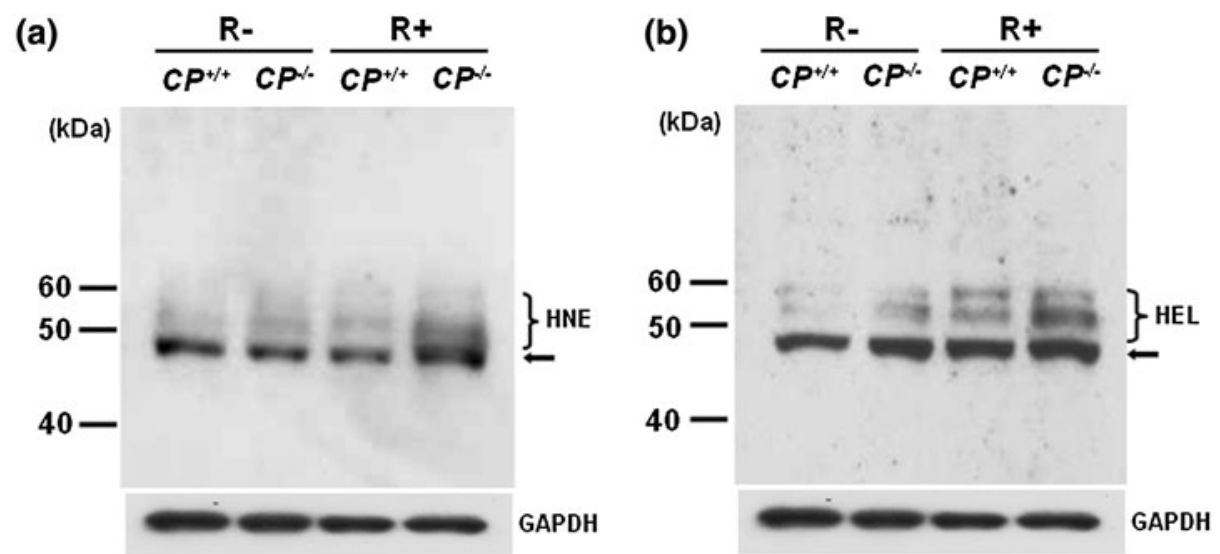

(c)

(d)

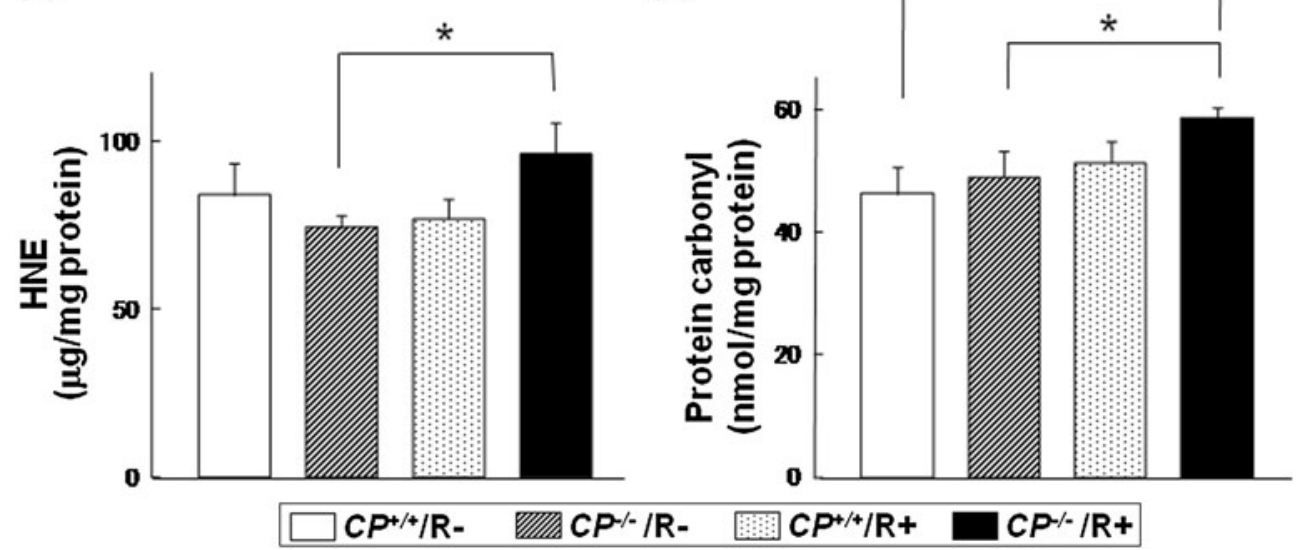

dopaminergic neurons in vivo and in vitro, and is frequently used to investigate the pathogenesis of Parkinson's disease [19-26]. According to the reported dosage of rotenone in mice $(2.5-100.0 \mathrm{mg} / \mathrm{kg} /$ day for $4-9$ weeks) [21, 23-26], we used rotenone at a comparatively lowdosage (10 mg/kg, 4 weeks). Thus, all the mice completed the protocol without any problems in their general health and the mean body weight was not significantly different between the four groups examined.

Rotenone did not cause a significant change in motor behavior, neuropathology, or the levels of oxidative stress markers in the presence of $\mathrm{Cp}$ in this study. On the other hand, it brought about an obvious motor dysfunction and increased levels of oxidative stress markers in the absence of $\mathrm{Cp}$. At the end of the 4-week rotenone treatment, $\mathrm{CP}^{-/-}$/ $\mathrm{R}+$ mice showed a slow and irregular gait with small steps, and they fell from the rotarod more easily than $C P^{+/+} / \mathrm{R}-$ mice. The levels of oxidative stress markers were increased in $C P^{-/-} / \mathrm{R}+$ mice when compared with $C P^{+/+} / \mathrm{R}-$ or $C P^{-/-} / \mathrm{R}-$ mice. In addition, we previously reported that immunoreactivity for acrolein and ubiquitin was enhanced in the brains of $C P^{-1-} / \mathrm{R}+$ mice [32]. Mitochondria are easily exposed to oxidative damage because they utilize large amounts of oxygen and iron, and contain numerous redox enzymes [36, 37]. In fact, there is a marked reduction in the activity of the respiratory chain complexes I and IV in the brains of aceruloplasminemia patients [11]. Thus, from the viewpoint of enhanced oxidative stress in the brain, our $\mathrm{CP}^{-1-}$ mice treated with a low dose of rotenone will be a more faithful model for aceruloplasminemia than conventional $\mathrm{CP}^{-/-}$mice.

But, rotenone treatment in our mice did not affect the mitochondrial complex I activities, probably because of the low dosage. Under this condition, however, $C P^{-1-}$ mice, not $C P^{+/+}$mice, showed a significant increase of oxidative stress markers in the brain and motor dysfunction. Rotenone is believed to cause neuron death by an inhibition of the mitochondrial complex I activities, but Choi et al. have suggested that neuronal cell death induced by rotenone is independent of mitochondrial complex I inhibition [38]. The present study may support that rotenone-induced neurotoxicity is mediated through alternative pathways other than mitochondrial complex I inhibition, and that such pathways are enhanced by Cp deficiency.

Our $C P^{-l-}$ mice with or without rotenone treatment showed no iron accumulation in the brain as far as we observed up to 60 weeks of age. The question is how $\mathrm{Cp}$ prevents neuronal cells from rotenone-induced 
Fig. 4 Immunohistochemistry for oxidative stress markers. Immunohistochemical staining using anti-HNE (a-d) and antiHEL (e-h) antibodies in the striatum is shown. $C P^{+/+} / \mathrm{R}-$ (a, e), $C P^{-/-} / \mathrm{R}-(\mathbf{b}, \mathbf{f}), C P^{+/+} /$ $\mathrm{R}+(\mathbf{c}, \mathbf{g})$, and $C P^{-l-} / \mathrm{R}+$ mice $(\mathbf{d}, \mathbf{h})$. Scale bars $=20 \mu \mathrm{m}$

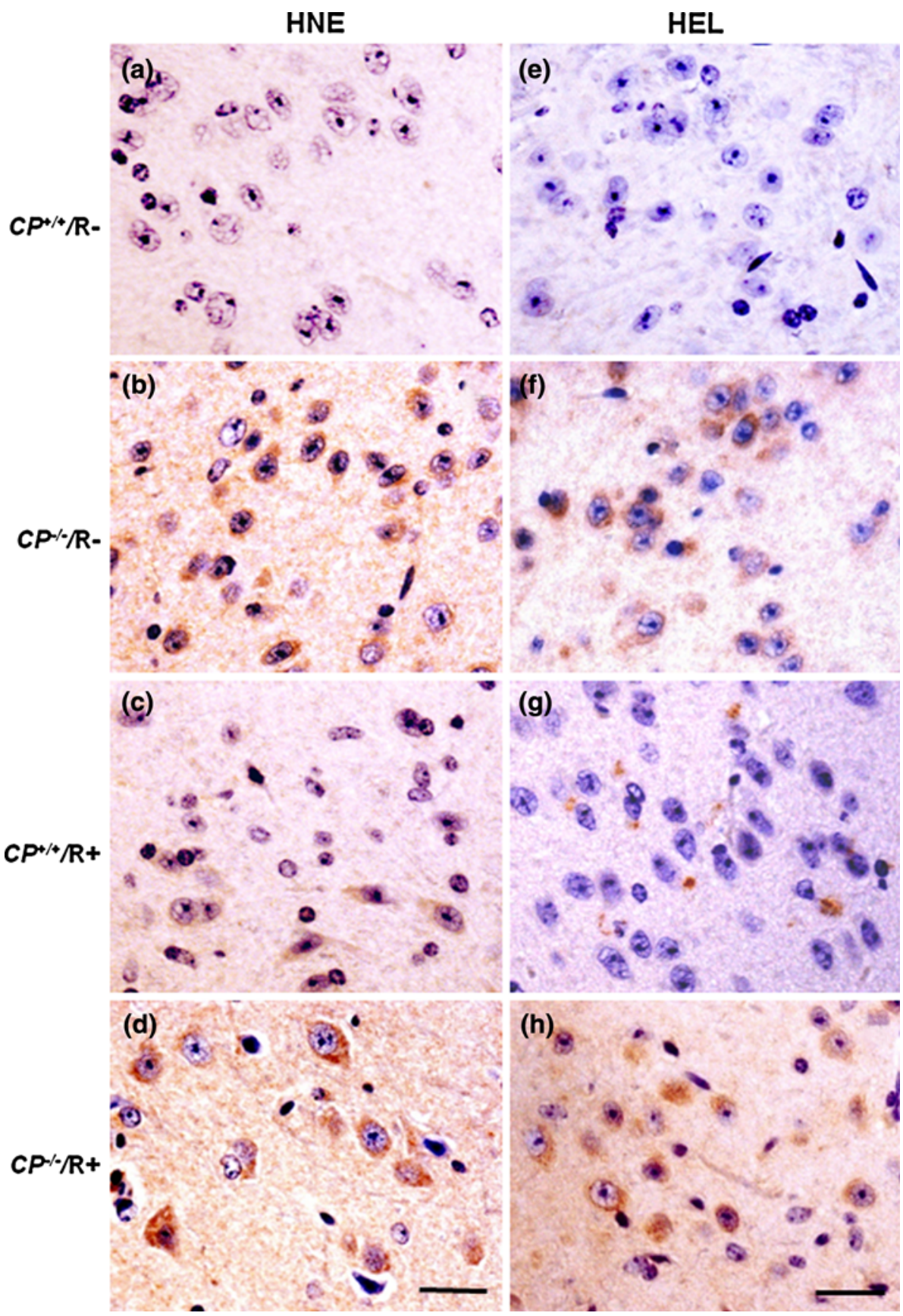

neurotoxicity under the circumstances without iron accumulation. $\mathrm{Cp}$ is considered to oxidize non-iron substrates such as catecholamines and aromatic amines [1, 2, 39]. For example, Cp oxidizes the neurotoxin, 6-hydroxydopamine, which is an intermediate in the formation of dopamine and melanins. 6-hydroxydopamine undergoes spontaneous autooxidation to yield several reactive oxygen species including $\mathrm{H}_{2} \mathrm{O}_{2}$ and $\mathrm{OH}^{\bullet}$. Unlike spontaneous autooxidation, 6-hydroxydopamine oxidation by $\mathrm{Cp}$ does not result in the production of $\mathrm{H}_{2} \mathrm{O}_{2}$ and $\mathrm{OH}^{\bullet}[2,39]$. Thus, one possible interpretation is that enhanced oxidative stress in our $C P^{-/-} / \mathrm{R}+$ mice could be due to a loss of $\mathrm{Cp}$-mediated oxidation of non-iron substrates. Moreover, Atanasiu et al. have shown that $\mathrm{Cp}$ is capable to scavenge peroxyl, superoxide radicals, and $\mathrm{OH}^{\bullet}$ even after heat inactivation of its oxidase activity [40]. These data strongly indicate that $\mathrm{Cp}$, besides its preventive antioxidant properties, has chain-breaking antioxidant property [40]. This is another possibility to explain that $C P^{-/-} / \mathrm{R}+$ mice showed motor dysfunction and increased oxidative stress markers when compared with $\mathrm{CP}^{+/+} / \mathrm{R}-$ mice. The antioxidant properties of $\mathrm{Cp}$ other than its ferroxidase activity may also explain 
why our $C P^{-/-} / \mathrm{R}-$ mice showed motor dysfunction when compared with $C P^{+/+} / \mathrm{R}-$ mice. Even, if it is the case, we speculate that an increase of oxidative stress markers in our $\mathrm{CP}^{-1-} / \mathrm{R}-$ mice was too subtle, or locally restricted to be detected by our assay methods using whole brain homogenates.

In summary, our $\mathrm{CP}^{-/-}$mouse model treated with rotenone indicates that $\mathrm{Cp}$ plays an important role in the neuroprotection against oxidative stress, even without apparent misregulation of iron homeostasis. To further elucidate the pathogenesis of aceruplasminemia, it will be needed to clarify how the alternative functions of $\mathrm{Cp}$, other than ferroxidase activity, is involved in this disease.

Open Access This article is distributed under the terms of the Creative Commons Attribution Noncommercial License which permits any noncommercial use, distribution, and reproduction in any medium, provided the original author(s) and source are credited.

\section{References}

1. Vassiliev V, Harris ZL, Zatta P (2005) Ceruloplasmin in neurodegenerative diseases. Brain Res Rev 49:633-640

2. Healy J, Tipton K (2007) Ceruloplasmin and what it might do. J Neural Transm 114:777-781

3. Floris G, Medda R, Padiglia A et al (2000) The physiopathological significance of ceruloplasmin. A possible therapeutic approach. Biochem Pharmacol 60:1735-1741

4. Patel BN, David S (1997) A novel glycosylphosphatidylinositolanchored form of ceruloplasmin is expressed by mammalian astrocytes. J Biol Chem 272:20185-20190

5. Ke Y, Quan ZM (2007) Brain iron metabolism: neurobiology and neurochemistry. Prog Neurobiol 83:149-173

6. Gaasch JA, Lockman PR, Geldenhuys WJ et al (2007) Brain iron toxicity: differential responses of astrocytes, neurons, and endothelial cells. Neurochem Res 32:1196-1208

7. Benarroch EE (2009) Brain iron homeostasis and neurodegenerative disease. Neurology 72:1436-1440

8. Morita H, Ikeda S, Yamamoto K et al (1995) Hereditary ceruloplasmin deficiency with hemosiderosis: a clinicopathological study of a Japanese family. Ann Neurol 37:646-656

9. Kaneko K, Yoshida K, Arima K et al (2002) Astrocytic deformity and globular structures are characteristic of the brains of patients with aceruloplasminemia. J Neuropathol Exp Neurol 61: 1069-1077

10. Oide T, Yoshida K, Kaneko K et al (2006) Iron overload and antioxidative role of perivascular astrocytes in aceruloplasminemia. Neuropathol Appl Neurobiol 32:170-176

11. Kohno S, Miyajima H, Takahashi Y et al (2000) Defective electron transfer in complexes I and IV in patients with aceruloplasminemia. J Neurol Sci 182:57-60

12. Yoshida K, Kaneko K, Miyajima H et al (2000) Increased lipid peroxidation in the brains of aceruloplasminemia patients. J Neurol Sci 175:91-95

13. Kaneko K, Nakamura A, Yoshida K et al (2002) Glial fibrillary acidic protein is greatly modified by oxidative stress in aceruloplasminemia brain. Free Radic Res 36:303-306

14. Yamamoto K, Yoshida K, Miyagoe Y et al (2002) Quantitative evaluation of expression of iron-metabolism genes in ceruloplasmin-deficient mice. Biochem Biophys Acta 1588:195-202
15. Zecca L, Youdim MBH, Riederer P et al (2004) Iron, brain ageing and neurodegenerative disorders. Nat Rev Neurosci 5:863-873

16. Whitnall M, Richardson DR (2006) Iron: a new target for pharmacological intervention in neurodegenerative diseases. Semin Pediatr Neurol 13:186-197

17. Molina-Holgado F, Hider RC, Gaeta A et al (2007) Metal ions and neurodegeneration. Biometals 20:639-654

18. Raha S, Robinson BH (2000) Mitochondria, oxygen free radicals, disease and ageing. Trends Biochem Sci 25:502-508

19. Betarbet R, Sherer TB, MacKenzie G et al (2000) Chronic systemic pesticide exposure reproduces features of Parkinson's disease. Nat Neurosci 3:1301-1306

20. Uversky VN (2004) Neurotoxicant-induced animal models of Parkinson's disease: understanding the role of rotenone, maneb and paraquat in neurodegeneration. Cell Tissue Res 318:225-241

21. Lapointe N, St-Hilaire M, Martinoli MG et al (2004) Rotenone induces non-specific central nervous system and systemic toxicity. FASEB J 18:717-719

22. Betarbet R, Canet-Aviles RM, Sherer TB et al (2006) Intersecting pathways to neurodegeneration in Parkinson's disease: effects of the pesticide rotenone on DJ-1, alpha-synuclein, and the ubiquitin-proteasome system. Neurobiol Dis 22:404-420

23. Richter F, Hamann M, Richter A (2007) Chronic rotenone treatment induces behavioral effects but no pathological signs of parkinsonism in mice. J Neurosci Res 85:681-691

24. Rojo AI, Cavada C, de Saqarra MR et al (2007) Chronic inhalation of rotenone or paraquat does not induce Parkinson's disease symptoms in mice or rats. Exp Neurol 208:120-126

25. Takeuchi H, Yanagida T, Inden M et al (2009) Nicotinic receptor stimulation protects nigral dopaminergic neurons in rotenoneinduced Parkinson's disease models. J Neurosci Res 87:576-585

26. Inden M, Kitamura Y, Abe M et al (2011) Parkinsonian rotenone mouse model: reevaluation of long-term administration of rotenone in C57BL/6 mice. Biol Pharm Bull 34:92-96

27. Saravanan KS, Sindhu KM, Mohanakumar KP (2007) Melatonin protects against rotenone-induced oxidative stress in a hemiparkinsonian rat model. J Pineal Res 42:247-253

28. Hosamani R, Muralidhara (2009) Neuroprotective efficacy of Bacopa monnieri against rotenone induced oxidative stress and neurotoxicity in Drosophila melanogaster. Neurotoxicology 30:977-985

29. Abdulwahid Arif I, Ahmad Khan H (2010) Environmental toxins and Parkinson's disease: putative roles of impaired electron transport chain and oxidative stress. Toxicol Ind Health 26:121-128

30. Tórsdóttir G, Sveinbjörnsdóttir S, Kristinsson J et al (2006) Ceruloplasmin and superoxide dismutase (SOD1) in Parkinson's disease: a follow-up study. Neurol Sci 241:53-58

31. Bharucha KJ, Friedman JK, Vincent AS et al (2008) Lower serum ceruloplasmin levels correlate with younger age of onset in Parkinson's disease. J Neurol 255:1957-1962

32. Kaneko K, Hineno A, Yoshida K et al (2008) Increased vulnerability to rotenone-induced neurotoxicity in ceruloplasmin-deficient mice. Neurosci Lett 446:56-58

33. Costa T, Constantino LC, Mendonça BP et al (2010) N-methylD-aspartate preconditioning improves short-term motor deficits outcome after mild traumatic brain injury in mice. J Neurosci Res 88:1329-1337

34. Kumakura K, Nomura H, Toyoda T et al (2010) Hyperactivity in novel environment with increased dopamine and impaired novelty preference in apoptosis signal-regulating kinase 1 (ASK1)deficient mice. Neurosci Res 66:313-320

35. Kudva IT, Griffin RW, Garren JM et al (2005) Identification of protein subset of anthrax spore immunome in humans immunized 
with the anthrax vaccine adsorbed preparation. Infect Immun 73:5685-5696

36. Andreyev AY, Kushnareva YK, Starkov AA (2005) Mitochondrial metabolism of reactive oxygen species. Biochemistry (Moscow) 70:200-214

37. Starkov AA (2008) The role of mitochondria in reactive oxygen species metabolism and signaling. Ann NY Acad Sci 1147:37-52

38. Choi W-S, Kruse SE, Palmiter RD et al (2008) Mitochondrial complex I inhibition is not required for dopaminergic neuron death induced by rotenone, $\mathrm{MPP}^{+}$, or paraquat. Proc Natl Acad Sci USA 105:15136-15141

39. Padiglia A, Medda R, Lorrai A et al (1997) Modulation of 6-hydroxydopamine oxidation by various proteins. Biochem Pharmacol 53:1065-1068

40. Atanasiu RL, Stea D, Mateescu MA et al (1998) Direct evidence of caeruloplasmin antioxidant properties. Mol Cell Biochem 189:127-135 